\title{
Efeito da aplicação de silicato de cálcio e de cinza de casca de arroz sobre a incidência de fungos associados a manchas em sementes de arroz irrigado
}

Rafaela Carolina Constantino Roma-Almeida ${ }^{1}$, Olinto Liparini Pereira ${ }^{1}$, Denise Cunha Fernandes dos Santos Dias ${ }^{2}$, Anne Sitarama Prabhu ${ }^{3}$, Marta Cristina Corsi de Filippi ${ }^{3}$, Henrique da Silva Silveira Duarte ${ }^{4}$ e Fabrício Ávila Rodrigues ${ }^{1}$

${ }^{1}$ Universidade Federal de Viçosa, Departamento de Fitopatologia, Av. P. H. Rolfs, s/n, CEP: 36500-000, Viçosa, MG, Brasil. ${ }^{2}$ Universidade Federal de Viçosa, Departamento de Fitotecnia, Av. P. H. Rolfs, s/n, CEP: 36500-000, Viçosa, MG, Brasil. ${ }^{3}$ Embrapa Arroz e Feijão, Rodovia GO-462, km 12, CEP: 75375-000, Santo Antônio de Goiás, GO, Brasil. ${ }^{4}$ Universidade Federal do Paraná, Departamento de Fitotecnia e Fitossanitarismo - R. dos Funcionários, 1540, Juvevê, CEP: 80035-050, Curitiba, PR.

Autor para correspondência: Rafaela Carolina Constantino Roma-Almeida (rafaelacroma@gmail.com)

Data de chegada: 07/07/2015. Aceito para publicação em: 04/11/2015.

$10.1590 / 0100-5405 / 2108$

\section{RESUMO}

Roma-Almeida, R.C.C.; Pereira, O.L.; Dias, D.C.F.S.; Prabhu, A.S.; Filippi, M.C.C.; Duarte, H.S.S.; Rodrigues, F.A. Efeito da aplicação de silicato de cálcio e de cinza de casca de arroz sobre a incidência de fungos associados a manchas em sementes de arroz irrigado. Summa Phytopathologica, v.42, n.1, p.73-78, 2016.

O objetivo deste trabalho foi avaliar o efeito da aplicação de silicato de cálcio e de cinza de casca de arroz (CCA) na incidência de fungos associados a manchas em sementes de arroz irrigado. Plantas de arroz foram submetidas à aplicação de silicato de cálcio ou CCA nas doses de 0,51,153, 256 e $357 \mathrm{~kg}$ $\mathrm{ha}^{-1}$ de silício (Si). Dois experimentos foram conduzidos, sendo um na safra 2007/2008 e outro na safra 2008/2009 e, posteriormente, amostras de sementes foram analisadas em laboratório. Foram realizadas avaliações do Índice de Escurecimento de Sementes (IES), da concentração de Si no pericarpo das sementes e a determinação da diversidade dos fungos presentes nas sementes. Não houve efeito das duas fontes de Si empregadas, nas doses utilizadas nos dois experimentos no IES e na concentração de Si. Os fungos fitopatogênicos encontrados em ambos experimentos foram Alternaria padwickiii, Bipolaris oryzae, Botrytis cinerea, Curvularia lunata, Fusarium semitectum, F. solani, Microdochium oryzae, Nigrospora oryzae, Phoma sorghina e Pyricularia oryzae. A incidência destes fungos não foi afetada pela aplicação das fontes de Si nas doses utilizadas.

Palavras-chave: Oryza sativa, mancha-de-grãos, patologia de sementes, silício.

\section{ABSTRACT}

Roma-Almeida, R.C.C.; Pereira, O.L.; Dias, D.C.F.S.; Prabhu, A.S.; Filippi, M.C.C.; Duarte, H.S.S.; Rodrigues, F.A. Effect of calcium silicate and rice husk ash application on the incidence of fungi associated with spots in flooded rice seeds. Summa Phytopathologica, v.42, n.1, p.73-78, 2016.

The aim of this study was to evaluate the effect of calcium silicate and rice husk ash (CCA) application on the incidence of fungi associated with spots in flooded rice seeds. Rice plants were subjected to application of calcium silicate or CCA at the levels of $0,51,153,256$ and $357 \mathrm{~kg} \mathrm{ha}^{-1}$ of silicon (Si). Two experiments were performed, one in the 2007/2008 crop season and another one in the 2008/2009 season; subsequently, seed samples were analyzed in laboratory. Evaluations were performed for Seed Browning Index (IES), Si concentration in the pericarp of the seeds and determination of the diversity of seedborne fungi. There was no effect of the two employed Si sources at the used levels in both experiments, for IES and Si concentration. The phytopathogenic fungi found in both experiments were Alternaria padwickiii, Bipolaris oryzae, Botrytis cinerea, Curvularia lunata, Fusarium semitectum, F. solani, Microdochium oryzae, Nigrospora oryzae, Phoma sorghina and Pyricularia oryzae. The incidence of these fungi was not affected by the application of Si sources at the used levels.

Keywords: Oryza sativa, grain discoloration, seed pathology, silicon.

O escurecimento do pericarpo, sintoma da doença conhecida como mancha de grãos, tem atingido a cultura do arroz em diversos países e tem gerado perdas para produção de grãos e sementes $(6,7,10,19)$. A doença ocorre desde a emissão das panículas até a maturidade dos grãos e pode ser causada por fungos como Drechslera spp., Bipolaris, spp., Pyricularia oryzae (Cooke) Sacc., Alternaria padwickii (Ganguly) M.B. Ellis, Gibberella fujikuroi (Sawada) Wollenw., Gibberella zeae (Schwein.) Petch, Nigrospora spp., Epicoccum spp., Curvularia spp., Phoma sorghina (Sacc.) Boerema, Dorenbosch \& Kesteren, Alternaria spp., dentre outros $(15,17)$. A severidade da mancha de grãos pode ocorrer em maior ou menor quantidade dependendo da variedade empregada e da intensidade de chuvas no período de emissão das panículas $(13,17,20)$. Os sintomas observados variam de manchas marrons pontuais até o completo escurecimento do pericarpo $(6,17)$.

Altos índices de manchas podem levar à redução na germinação das sementes de arroz em cerca de $27 \%(7,18)$, trazendo problemas para a obtenção do estande final. Para evitar danos excessivos na produção, o manejo integrado deve ser empregado, pois a aplicação de fungicidas não tem apresentado eficiência no controle da doença, principalmente em plantios tardios $(19,23)$. Dentre as principais medidas de controle, destacam-se o tratamento de sementes com fungicidas protetores, escolha do local de plantio, rotação de culturas, adubação equilibrada, eliminação de plantas hospedeiras, seleção de variedades resistentes e inspeções no campo de produção (16), que auxiliam na obtenção de plantas sadias e, consequentemente, de sementes de melhor qualidade sanitária e fisiológica. 
Na busca de métodos alternativos no manejo de doenças de plantas, estudos com produtos em cuja composição contenha silício (Si) têm sido realizados principalmente na cultura do arroz, que é uma planta considerada acumuladora desse elemento $(2,4,9,10,26)$. Além do efeito sobre as doenças, a aplicação de Si tem diversos efeitos em plantas como resistência a estresses abiótico e biótico $(4,24)$.

Estudos mostram que a aplicação de Si proporciona resultados significativos na redução da severidade e incidência da mancha dos grãos de arroz de arroz $(10,21,26,29)$. Seebold et al. (26) observaram decréscimo de até $26 \%$ na severidade do escurecimento de grãos em plantas supridas com Si. A eficácia do Si sobre o controle de doenças é reconhecida na literatura, porém há poucas descrições sobre os efeitos da aplicação deste elemento na qualidade sanitária de sementes (3). Além dos silicatos, uma fonte alternativa de Si é a cinza de casca de arroz $(12,25)$, que apesar de possuir menor teor de Si em sua constituição $(7,1 \%)$, quando comparado com as escórias da indústria siderúrgica que possuem em torno de $10 \%$, é um produto de baixo custo (24), pois torna-se um resíduo durante o beneficiamento do produto.

Desta forma, o objetivo deste trabalho foi avaliar o efeito da aplicação de silicato de cálcio e de cinza de casca de arroz na incidência de fungos associados a manchas em sementes de arroz irrigado.

\section{MATERIAL E MÉTODOS}

\section{Instalação dos experimentos}

Os ensaios foram conduzidos em área experimental da Embrapa - Centro Nacional de Pesquisa Arroz e Feijão (CNPAF). A análise química do solo no ano de 2007, anteriormente a aplicação de $\mathrm{Si}$, indicou a seguinte composição: $\mathrm{pH} 4,4 \mathrm{em}$ água, $\mathrm{P}=43,9 \mathrm{mg} \mathrm{dm}^{-3}, \mathrm{~K}$ $=39,0 \mathrm{mg} \mathrm{dm}^{-3}, \mathrm{Al}=1,4 \mathrm{cmol} \mathrm{dm}^{-3}, \mathrm{Ca}=0,63 \mathrm{cmol} \mathrm{dm}^{-3}, \mathrm{Mg}=0,26$ $\mathrm{cmol} \mathrm{dm}^{-3}, \mathrm{H}+\mathrm{Al}=5,61 \mathrm{cmol} \mathrm{dm}^{-3}, \mathrm{Cu}=3,8 \mathrm{mg} \mathrm{dm}^{-3}, \mathrm{Zn}=4,0 \mathrm{mg}$ $\mathrm{dm}^{-3}, \mathrm{Fe}=500 \mathrm{mg} \mathrm{dm}^{-3}, \mathrm{Mn}=20 \mathrm{mg} \mathrm{dm}^{-3}$ e matéria orgânica $=113 \mathrm{~g}$ $\mathrm{dm}^{-3}$, enquanto que a concentração de Si no solo foi de $4,9 \mathrm{mg} \mathrm{Kg}^{-1}$.

As doses de silicato de cálcio (Agrosilício ${ }^{\circledR}$, Excell Minerais e Fertilizantes Ltda) e de cinza de casca de arroz (CCA), além de calcário (253 $\left.\mathrm{kg} \mathrm{ha}^{-1}\right)$, foram aplicadas em gleissolo húmico de várzea, 30 dias antes da semeadura de plantas de arroz da cultivar BRS alvorada, recomendada para o cultivo em várzeas. Estes produtos foram aplicados a lanço e, em seguida, incorporados ao solo a partir de uma aração e duas gradagens. Foram utilizados $400 \mathrm{~kg} \mathrm{ha}^{-1}$ de N-P-K (5-30-15), como adubação de plantio, e $100 \mathrm{~kg} \mathrm{ha}^{-1}$ de ureia aos 28 e 69 dias após o plantio. A irrigação por alagamento iniciou-se 29 dias após o plantio.

As doses de silicato de cálcio foram 0,$0 ; 0,48 ; 1,43 ; 2,38 ; 3,34 \mathrm{t}$

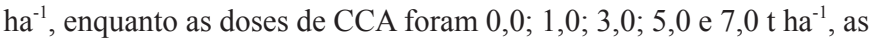
quais correspondem, para ambos os produtos, a 0,$0 ; 51,0 ; 153,0 ; 256,0$ e $357,0 \mathrm{~kg} \mathrm{ha}^{-1} \mathrm{de} \mathrm{Si}$, as quais foram calculadas com base na análise de solo. Visando isolar o efeito do Si fornecido pelo SC e pela CCA, procedeu-se a adição de carbonato de cálcio e carbonato de magnésio com o objetivo de equilibrar as concentrações de cálcio e magnésio aplicadas em todos os tratamentos para que houvesse variação apenas nas doses de Si empregadas.

Foram conduzidos dois experimentos, o primeiro na safra 2007/2008 (ano 1) e o segundo na 2008/2009 (ano 2), sendo que a aplicação das fontes de Si foi realizada apenas no experimento 1 . O segundo experimento foi instalado para avaliação do efeito residual dos produtos aplicados na safra 2007/2008. Após o cultivo das plantas de arroz em solo onde foram instalados os tratamentos, amostras de sementes de cada experimento foram coletadas (conforme item delineamento experimental e análises estatísticas) e encaminhadas para laboratório para as análises de escurecimento de sementes, concentração de Si e teste de sanidade.

\section{Índice de Escurecimento de Sementes}

Para determinação do Índice de Escurecimento de Sementes (IES) foram retiradas aleatoriamente 200 sementes de cada unidade experimental para cada tratamento e estas foram submetidas à análise visual, com o auxílio de uma escala de notas, sugerida pelo "International Rice Research Institute" (8), onde $\mathbf{0}=0 \%, \mathbf{1}=<1 \%, \mathbf{3}=$ $1-5 \%, \mathbf{5}=6-25 \%, 7=26-50 \%$ e $\mathbf{9}=>50 \%$ de manchas presentes na superfície da semente. Após atribuição das notas de severidade de manchas em sementes, os dados foram aplicados ao Índice de McKinney (14) para obtenção do IES através da seguinte fórmula:

$$
\mathrm{IES}=\frac{\sum(\mathrm{f} . v)}{\mathrm{n} \cdot \mathrm{x}} \cdot 100
$$

Em que: IES = índice de escurecimento de sementes; $\mathrm{f}=$ número de sementes com determinada nota de severidade; $\mathrm{v}=$ nota observada; $\mathrm{n}$ $=$ número de sementes analisadas; $\mathrm{e} \mathrm{x}=$ a maior nota da escala.

Determinação da concentração de Si no pericarpo das sementes

Para avaliação da concentração de Si no pericarpo das sementes, procedeu-se a separação do pericarpo do endosperma. Em seguida, o pericarpo das sementes de arroz foi triturado com a utilização de um moinho tipo Willey. Após este procedimento, aproximadamente 0,1 $\mathrm{g}$ de material foi depositado em tubo de microcentrífuga, de forma que, para cada unidade experimental foram realizadas 3 amostragens. A concentração de Si foi determinada de acordo com Korndörfer et al. (11).

\section{Teste de sanidade de sementes}

A diversidade fúngica das amostras de sementes de plantas de arroz cultivadas em solo que recebeu aplicação de silicato de cálcio e CCA foi determinada por meio de um teste de sanidade, utilizando-se o método do Papel-Filtro, também conhecido como Blotter Test (16). Foram utilizadas 200 sementes para a execução deste teste. Para a desinfestação superficial, procedeu-se a imersão das sementes em álcool $50 \%$ por 1 minuto, seguido de hipoclorito de sódio $1 \%$ também por 1 minuto e, por último, em água estéril pelo mesmo período. Posteriormente, as sementes foram dispostas sobre papel-filtro umedecido, em gerbox e, em seguida, em geladeira por $24 \mathrm{~h}$ e, após este período, em congelador por $48 \mathrm{~h}$. Após este procedimento, as sementes foram incubadas em câmaras tipo B.O.D. à temperatura de $28{ }^{\circ} \mathrm{C}$, com fotoperíodo de 12 $\mathrm{h}$ onde permaneceram por seis dias, até o aparecimento dos sinais dos microrganismos. Em seguida, para obtenção da incidência dos fungos, as sementes foram analisadas individualmente com o auxílio de microscópio estereoscópico e microscópio de luz, quando necessário. Exceto para Penicillium sp., Botryotrichum sp. e Chaetomium sp., procedeu-se a identificação a nível de espécie fúngica, utilizando-se de chaves taxonômicas $(1,27)$.

\section{Delineamento experimental e análise estatística dos dados}

O delineamento utilizado foi de blocos ao acaso, em esquema de parcelas subdivididas, com quatro repetições. As parcelas continham os produtos empregados (silicato de cálcio e CCA) e as subparcelas, as doses de cada uma das fontes. A dose zero, onde foi realizada apenas aplicação de calcário, foi considerada testemunha, pois não recebeu Si. Cada subparcela, o que correspondeu a uma unidade experimental, correspondeu a 12 linhas de 5,0 m de comprimento 
cada e o espaçamento entre linhas foi de $0,17 \mathrm{~m}$, sendo que a área total da subparcela foi de 10,2 $\mathrm{m}^{2}$. Para avaliação, foram consideradas as quatro linhas centrais da subparcelas, o que corresponde a uma área útil de 3,2 $\mathrm{m}^{2}$. A amostragem foi realizada nas duas linhas laterais da área útil da subparcela, à partir da coleta de 10 plantas de cada linha, perfazendo um total de 20 plantas. O espaçamento entre parcelas e subparcelas foi de $1,5 \mathrm{~m}$.

Os dados obtidos foram submetidos à verificação das pressuposições de normalidade, homogeneidade e independência dos erros e pela análise de variância. A análise de regressão foi baseada nas doses e nas fontes de Si para as variáveis IES, concentração de Si e incidência dos fungos. As análises estatísticas foram realizadas através do programa MiniTab.

Para análise estatística, as fontes de Si silicato de cálcio e CCA foram codificadas como 0 e 1 , respectivamente. Os coeficientes mais elevados para o modelo usado foram testados pelo teste $t$ de Student $(P$ $<0,05)$ para melhor ajuste de modelo com todos os termos significativos apresentados a seguir:

$$
\mathrm{Y}_{\mathrm{i}}=\beta_{0}+\beta_{1} \mathrm{D}_{\mathrm{i}}+\beta_{2} \mathrm{D}_{\mathrm{i}}^{2}+\beta_{3} \mathrm{~F}_{\mathrm{i}}+\beta_{4} \mathrm{D}_{\mathrm{i}} \mathrm{F}_{\mathrm{i}}+\mathrm{e}_{\mathrm{i}}
$$

onde $\mathrm{Y}_{\mathrm{i}}=$ valor observado na variável em observação $\mathrm{i}(\mathrm{i}=1,2,3 \ldots$, 40); $\mathrm{D}_{\mathrm{i}}=$ dose de Si na observação i $\left(0,51,153,256\right.$ e $\left.357 \mathrm{~kg} \mathrm{ha}^{-1}\right) ; \mathrm{F}_{\mathrm{i}}$ $=$ fontes de Si na observação i $(0=$ silicato de cálcio e $1=\mathrm{CCA}) ; \beta_{0}=$ constante de regressão; $\beta_{1}, \beta_{2}, \beta_{3}$ and $\beta_{4}=$ coeficientes de regressão e e ${ }_{i}$ $=0$ erro na regressão associado com o valor observado em $Y_{i}$.

\section{RESULTADOS E DISCUSSÃO}

A aplicação de diferentes doses de silicato de cálcio ou CCA não proporcionou redução no IES $(P<0,05)$ (Figura 1). Para tratamentos com aplicação de silicato de cálcio e CCA, o IES no primeiro ano foi de aproximadamente 48,6 e 45,5, respectivamente (Figura 1a). No segundo ano, os valores de IES foram 45,6 para silicato de cálcio e 46,2 para CCA (Figura 1b). Isto indica que não houve influência da aplicação de fontes de silício, nas doses utilizadas, nem mesmo do efeito residual dos produtos na ocorrência do escurecimento das sementes. Um fator que pode ter afetado a análise é a possível presença do percevejo das panículas (Oebalus sp.) que, devido ao seu hábito de alimentação, gera pontuações no pericarpo da semente (5), semelhantes às manchas causadas por agentes etiológicos associados à mancha de grãos. Além disso, as picadas de alimentação geram portas de entrada, as quais favorecem a infecção de microrganismos (7).

Semelhantemente ao observado para o IES, não houve aumento na concentração de Si no pericarpo das sementes de arroz em função dos tratamentos utilizados $(P<0,05)$ (Figura 2). A concentração de Si no pericarpo de sementes de arroz de plantas fertilizadas com silicato de cálcio foi, em média, de 3,65 e 4,26 dag $\mathrm{kg}^{-1}$ nos anos 1 e 2, respectivamente (Figura 2a). Já para sementes dos tratamentos que receberam aplicação de CCA, a concentração de Si foi de 3,56 dag kg-1 no ano 1 e 3,94 dag kg-1 no ano 2, em média (Figura 2b). No tratamento testemunha de silicato de cálcio, as concentrações foram de 4,01 e 4,46 dag $\mathrm{kg}^{-1}$, nos anos 1 e 2, respectivamente, enquanto que, no tratamento testemunha de CCA, as concentrações de Si foram de 3,69 e 4,01 dag $\mathrm{kg}^{-1}$ nos anos 1 e 2 , respectivamente.

Em plantas de arroz, concentrações elevadas de Si são encontradas no pericarpo das sementes, seguido pela folha bandeira e pelo pescoço da panícula (21). Segundo Winslow et al. (30), concentrações de Si no pericarpo entre 30 e $60 \mathrm{~g} \mathrm{~kg}^{-1}$, o que corresponde a 3 a $6 \mathrm{dag} \mathrm{kg}^{-1}$ do peso das sementes, estão nos limites entre a deficiência e a adequação do elemento nesta parte da planta. Os resultados encontrados nesta pesquisa para quaisquer tratamentos, tanto no ano 1 quanto no ano 2 , apresentaram-se abaixo de 6 dag $\mathrm{kg}^{-1}$. Estes resultados sugerem uma possível suscetibilidade da planta à doença, devido ao teor de Si ter se apresentado abaixo da adequação.

Foram detectados fungos fitopatogênicos e saprófitas nas sementes obtidas das plantas dos dois anos de cultivo (Tabela 1). Os coeficientes da regressão para a variável incidência tanto para os fungos fitopatogênicos quanto para os saprófitas não foram significativos $(P$ $<0,05)$, mostrando que não houve redução na incidência dos fungos nas sementes com o aumento das doses nas diferentes fontes de $\mathrm{Si}$. No ano 1, as maiores incidências foram para Microdochium oryzae, Cladosporium cladosporioides, Bipolaris oryzae, Phoma sorghina A. padwickii e $N$. oryzae com valores médios de incidência de 23,$75 ; 12,40$; 6,$97 ; 6,97 ; 5,62$ e $1,95 \%$, respectivamente, quando foram aplicados o
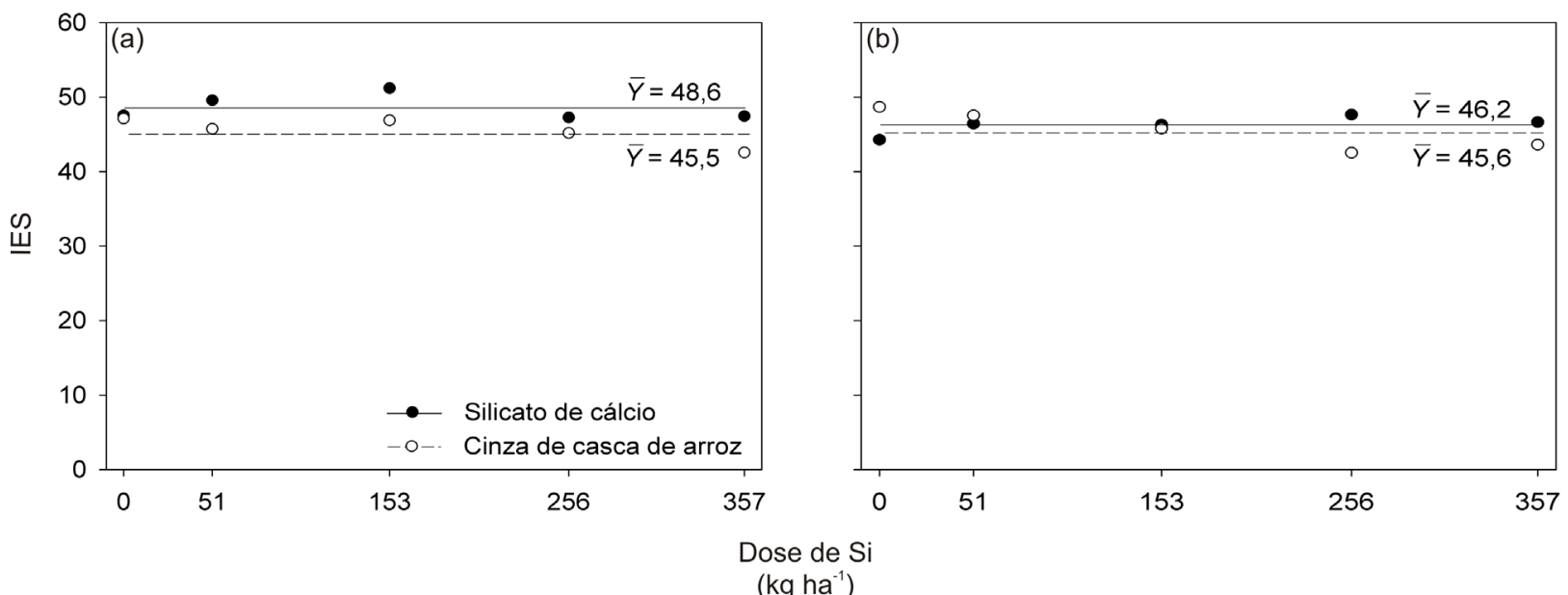

Dose de Si

$\left(\mathrm{kg} \mathrm{ha}^{-1}\right)$

Figura 1. Índice de escurecimento de sementes (IES) de sementes provenientes de plantas de arroz supridas ou não (dose 0) com silicato de cálcio ou cinza de casca de arroz em dois experimentos realizados em dois anos consecutivos. A aplicação das fontes de Si foi realizada apenas no experimento 1. (a): experimento 1 e (b): experimento 2 . 


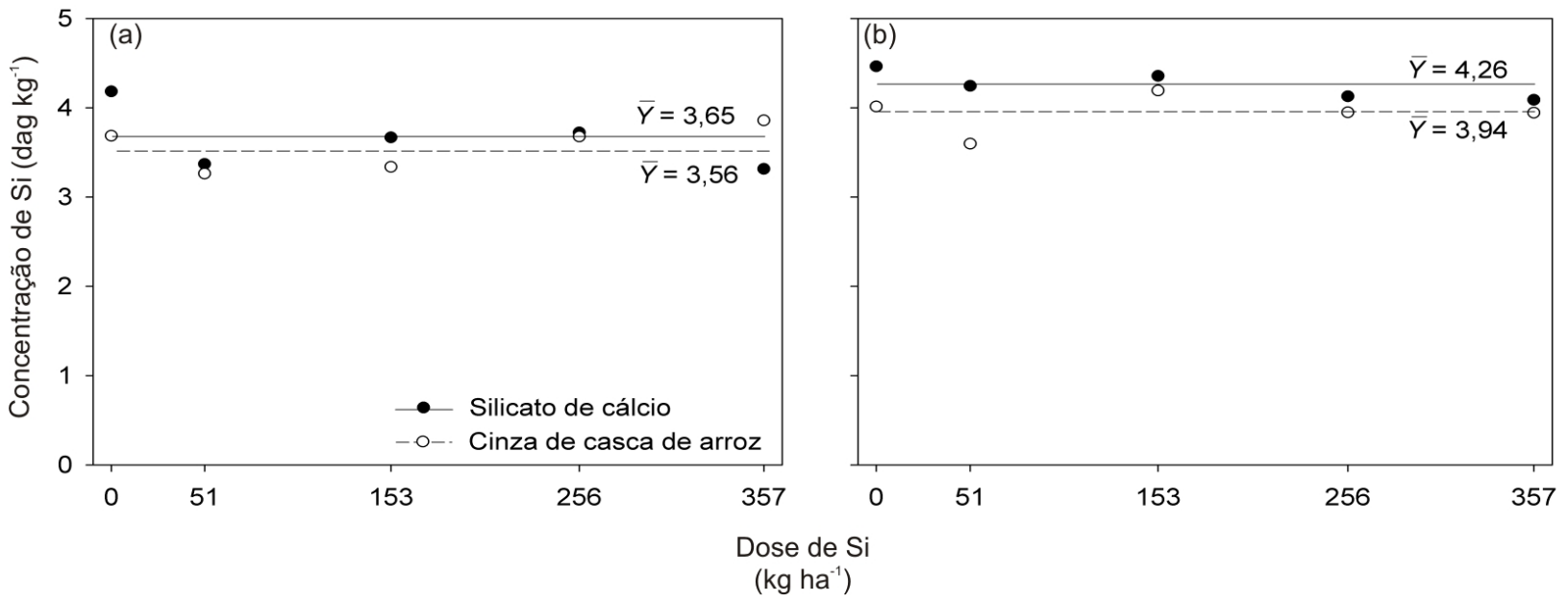

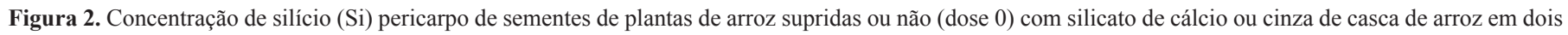
experimentos realizados em dois anos consecutivos. A aplicação das fontes de Si foi realizada apenas no experimento 1. (a): experimento 1 e (b): experimento 2

silicato de cálcio e com valores médios de incidência de 25,47; 9,00; 8,$45 ; 11,57 ; 5,70$ e $2,53 \%$, respectivamente, quando foram aplicados o CCA. No ano 2, as maiores incidências foram para M. oryzae, $B$. oryzae, $P$. sorghina, $N$. oryzae, A. padwickii e C. cladosporioides com valores médios de incidência de 13,$20 ; 5,85 ; 10,62 ; 8,77 ; 5,95$ e $7,20 \%$, respectivamente, quando foram aplicados o silicato de cálcio e com valores médios de incidência de 14,$70 ; 3,89 ; 17,60 ; 11,17 ; 6,30$ e $6,40 \%$, respectivamente, quando foram aplicados o CCA. Para os demais fungos encontrados (B. cinerea, C. lunata, F. semitectum, $F$. solani, F. oxysporum, Penicillium sp., P. oryzae, Chaetomium sp. e Botryotrichum sp.) a incidência nas sementes foi menor que $1,5 \%$ e, no geral, os fungos foram encontrados em apenas algumas doses dos produtos utilizados para os dois anos (Tabela 1).

Fungos fitopatogênicos e/ou saprófitas podem, naturalmente, ser encontrados em lotes de sementes. Em sementes de arroz que apresentam escurecimento do pericarpo, diversos fungos podem estar associados como B. oryzae, P. oryzae, A. padwickii, G. fujikuroi, G. zeae, Nigrospora spp., Epicoccum spp., Curvularia spp., P. sorghina, Alternaria spp., Aspergillus spp., Penicillium spp. e Cladosporium sp., dentre outros $(1,7,6)$. Entretanto, a ocorrência e a intensidade dos principais fungos associados à doença variam de um ano para o outro, embora os sintomas sejam semelhantes (28). Isso explica a pequena variação nas espécies fúngicas detectadas nas duas safras estudadas.

No presente trabalho ficou evidenciado que as doses de $\mathrm{Si}$ utilizadas, independente da fonte empregada, não proporcionaram redução do escurecimento das sementes analisadas. Estes resultados diferem das informações encontradas na literatura que relatam que o aumento da quantidade aplicada deste elemento gera redução na intensidade da doença $(10,21,26)$. Segundo estes autores, a aplicação de fontes deste elemento proporcionou aumento do teor de $\mathrm{Si}$ em tecidos da planta e decréscimo de manchas no pericarpo de grãos de arroz (10, 21,26). Entretanto, as condições em que estes autores conduziram seus experimentos diferem das empregadas neste trabalho. Estes autores implantaram seus experimentos no cultivo em terras altas e cultivares condizentes com esta forma de manejo, enquanto que, neste trabalho, foi utilizado sistema de cultivo irrigado e, consequentemente, uma cultivar adequada a esta condição.

Em áreas onde ocorre o plantio do arroz irrigado há aumento do fornecimento de $\mathrm{Si}$ à cultura, ou seja, esta condição favorece a disponibilidade deste elemento à planta (21). Desta forma, como a disponibilidade de Si é maior em cultivo irrigado, comparado com lavouras de cultivo em terras altas, uma hipótese é que a ocorrência do escurecimento nesta área poderia ser baixa e, por isso, a aplicação tanto de silicato de cálcio quanto de CCA, visando suprimento de $\mathrm{Si}$, não resultou em redução expressiva da doença. Apesar do favorecimento da disponibilidade de $\mathrm{Si}$ em ambientes irrigados, o estudo da aplicação deste elemento se faz necessária devido à ocorrência da doença nesta condição de cultivo.

Neste experimento foram empregadas as doses de 0, 51, 153, 256 e $357 \mathrm{~kg} \mathrm{ha}^{-1}$ de Si, de acordo com a análise do solo. Já Korndörfer et al. (10) utilizaram as doses de 0,120, 240, 480 e $960 \mathrm{~kg} \mathrm{ha}^{-1}$ de Si, enquanto Seebold et al. (26) 0, 500 e $1000 \mathrm{~kg} \mathrm{ha}^{-1}$ de Si e, em ambos os estudos, foram verificadas reduções na incidência de mancha-de-grãos, sendo que, no trabalho conduzido por Seebold et al. (26), observou-se que a aplicação de 1,0 tha $^{-1}$ de silicato de cálcio proporcionou $26 \%$ de redução na severidade do escurecimento do pericarpo. Estas expressivas reduções na ocorrência da doença encontradas por estes autores podem ser devido às condições de condução dos experimentos diferentes deste trabalho e, por isso, houve divergência nos resultados encontrados. Entretanto, Santos et al. (22) estudaram o efeito da aplicação de silício em arroz irrigado e verificaram que doses crescentes deste elemento não geraram redução na intensidade da doença, o que corrobora com este trabalho.

O escurecimento do pericarpo é um importante fator de degradação de sementes (16) sendo que, os fungos envolvidos neste fenômeno em sementes de arroz podem levar à redução na germinação e, consequentemente, diminuição no estande em sementeiras e em campo, esterilidade de panículas, redução do peso de 1000 sementes e, consequentemente, redução na produção $(15,18)$. Apesar da aplicação de Si não ter proporcionado redução na ocorrência da doença, o emprego de fertilizantes silicatados, juntamente com a adoção do manejo integrado, é necessário para o desenvolvimento da lavoura, auxiliando no controle de outras doenças importantes à cultura.

\section{AGRADECIMENTOS}

À Coordenação de Aperfeiçoamento de Pessoal de Nível Superior (CAPES) pela bolsa de estudos concedida à primeira autora. Ao Prof. Onkar Dev Dhingra pelas sugestões durante o desenvolvimento do trabalho. 
Tabela 1. Incidência de fungos fitopatogênicos e saprófitas em sementes de plantas de arroz supridas ou não (dose 0) com diferentes doses de silicato de cálcio nos anos 1 e 2 . A aplicação do silicato de cálcio foi realizada apenas no primeiro ano de cultivo.

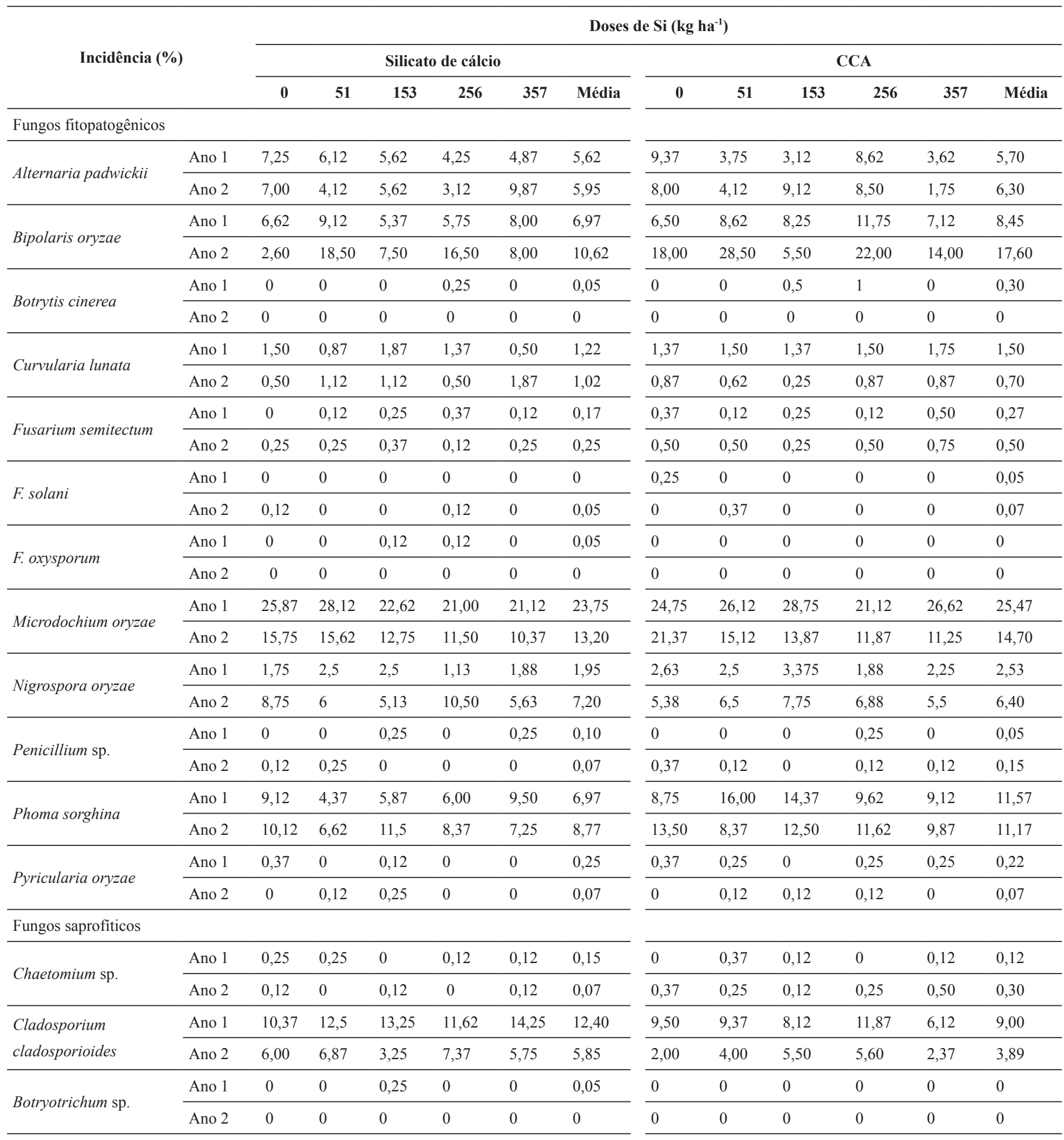

\section{REFERÊNCIAS}

1. Carmichael, J.W.; Brycekendrick, W.; Conners, I.L.; Sigler, L. Genera of Hyphomycetes. Alberta: The University of Alberta Press. 1980, 386p.

2. Datnoff, L.E.; Deren, C.W.; Snyder, G.H. Silicon fertilization for disease management of rice in Florida. Crop Protection, Guildford, v.16, n.6, p.525-531, 1997.

3. Dallagnol, L.J.; Rodrigues, F.A.; Mielli, M.V.B. Silicon improves the emer- gence and sanity of rice seedling obtained from seeds infected with Bipolaris oryzae. Tropical Plant Pathology, Brasília, v.33, n.6, p.478-484, 2013.

4. Epstein, E. Silicon. Annual Review of Plant Physiology and Plant Molecular Biology, Palo Alto, v.50, p.641-664, 1999.

5. Ferreira, E.; Barrigossi, J.A.F. Produção e qualidade de grãos de arroz infestados por adultos de percevejo-das-panículas. Pesquisa Agropecuária Brasileira, Brasília, v.41, p.1083-1091, 2006.

6. Huang, S.W.; Wang, L.; Liu, L.M.; Tang, S.Q.; Zhu, D.F.; Savary, S. Rice 
spikelet rot disease in China - 1. Characterization of fungi associated with the disease. Crop Protection, Guildford, v.30, p.1-9, 2011a.

7. Huang, S.W.; Wang, L.; Liu, L.M.; Tang, S.Q.; Zhu, D.F.; Savary, S. Rice spikelet rot disease in China-2. Pathogenicity testes, assessment of the importance of the disease, and preliminary evaluation of control options. Crop Protection, Guildford, v.30, p.10-17, 2011b.

8. IRRI - International Rice Research Institute. Standard evaluation system for rice. Manila: International Rice Research Institute, 1996. 52 p.

9. Kim, S.G.; Kim, K.W.; Park, E.W.; Choi, D. Silicon-induced cell wall fortification of rice leaves: a possible cellular mechanism of enhanced host resistance to blast. Phytopathology, Saint Paul, v.92, p.1095-1103, 2002.

10. Korndörfer, G.H.; Datnoff, L.E.; Corrêa, G.F. Influence of silicon on grain discoloration and upland rice grown on four savanna soils of Brazil. Journal of Plant Nutrition, New York, v.22, p.93-102, 1999.

11. Korndörfer, G.H.; Pereira, H.S.; Nolla, A. Análise de silício: solo, planta e fertilizante. Boletim Técnico 2, Grupo de Pesquisa em Silício, ICIAG Universidade Federal de Uberlândia, 2004. 34p.

12. Lanning, F.C. Silicon in Rice. Journal of Agriculture and Food Chemistry, Davis, v.11, p.435-437, 1963.

13. Malavolta, V.M.A.; Soligo, E.A.; Dias, D.D.; Azzini, L.E.; Bastos, C.R. Incidência de fungos e quantificação de danos em sementes de genótipos de arroz. Summa Phytopathologica, Jaguariuna, v.33, p.280-286, 2007.

14. McKinney, R.H. Influence of soil temperature and moisture on infection of wheat seedlings by Helminthosporium sativum. Journal of Agricultural Research, Washington, v.6, p.195-218, 1923.

15. Mew, T.W.; Gonzales, P. A hand-book of rice seedborne fungi. Los Baños: Science Publishers, Inc, 2002 83p.

16. Neergaard, P. Seed Pathology 2 ed. London: The Macmillan Press LTD, 1979. 839p.

17. Ou, S.H. Rice diseases. 2 ed. Kew: Commonwealth Agricultural Bureau, 1985, 380p.

18. Phat, C.T.; Duong, N.T.; Du, L.T. Influence of grain discoloration to seed quality. Omonrice, Omon, v.13, p.139-144, 2005. Short Communication.

19. Pizzatti, C.; Cortesi, P. Effect of chemicals, nitrogen, time of sowing and panicle brown spot epidemics on rice grain discolouration in Italy. Journal of Plant Pathology, Bari, v.90, p.197-209, 2008.

20. Prabhu, A.S. Situação atual do arroz de sequeiro e estratégias de controle. Fitopatologia Brasileira, Brasília, v.20, p.277, 1995.

21. Prabhu, A.S.; Barbosa Filho, M.P.B.; Datnoff, L.E.; Snyder, G.H.; Berni, R.F.; Rodrigues, F.A.; Dallagnol, L.J. Silicon reduces brown spot severity and grain discoloration in several rice genotypes. Tropical Plant Pathology, Brasília, v. 37, n. 6, p. 409-414, 2012.

22. Santos, G.R.; Korndörfer, G.H.; Reis Filho, J.C.D.; Pelúzio, J.M.. Adubação com silício: influência sobre as principais doenças e sobre a produtividade do arroz irrigado por inundação. Revista Ceres, Viçosa, v.50, p. 1-8, 2003.

23. Santos, G.R.; Chagas, J.F.R.; Tavares, A.T.; Castro Neto, M.D.; Sarmento, R.A.; Chagas Junior, A.F.; Nascimento, I.R. Danos causados por doenças fúngicas no arroz cultivado em várzeas no Sul do Estado do Tocantins. Bragantia, Campinas, v. 70, n. 4, p.869-875, 2011.

24. Savant, N.K.; Snyder, G.H.; Datnoff, L.E. Silicon management and sustainable rice production. Advances in Agronomy, San Diego, v.58, p.151-199, 1997.

25. Sawant, A.S.; Patil, V.H.; Savant, N.K. Rice hull ash applied to seedbed reduces deadhearts in transplanted rice. International Institute Rice Research Notes, Los Baños, v.19, p.21-22, 1994.

26. Seebold, K.W.; Datnoff, L.E.; Correa-Victoria, F.J.; Kucharek, T.A.; Snyder, G.H. Effect of silicon rate and host resistance on blast, scald, and yield of upland rice. Plant Disease, Saint Paul, v.84, p.871-876, 2000.

27. Sutton, B.C. The Coelomycetes. Kew: Commonwealth Mycological Institute, $1980.696 \mathrm{p}$.

28. Tanaka, M.A.S. Fungos associados a sementes de arroz com descoloração de grãos em Minas Gerais. Revista Brasileira de Sementes, Brasília, v.8, p.85-89, 1986.

29. Winslow, M.D. Silicon, disease resistance, and yield of rice genotypes under upland cultural conditions. Crop Science, Madison, v.32, 1208-1213, 1992.

30. Winslow, M.D.; Okada, K.; Correa-Victoria, F. Silicon deficiency and the adaptation of tropical rice ecotypes. Plant and Soil, The Hague, v.188, p.239-248, 1997. 